\title{
LA SOCIOLOGIA DE FREUD
}

\author{
Juan F. Marsal \\ (Universidad Autónoma de Barcelona)
}

El autor analiza, en primer lugar, someramente en qué consiste la revolución freudiana que centra en las áreas de la sexualidad infantil, la negación de la antinomia normal-anormal, el inconsciente, los suef̃os y el nuevo entendimiento de una esfera ampliada de la sexualidad y los afectos. Pero la obra de Freud no se tefiere únicamente al conocimiento sino que consiste en un intento de transformación del ser humano neurótico por medio de la terapia. En una segunda parte este trabajo trata de la teoría social de Freud propiamente. Aparte de su influencia indiscutible tanto en la teoría como en la metodología sociológica, Freud aporta una verdadera antropología no exenta de contaminación psicologista y evolucionista. El autor del trabajo ve incluso una inesperada coincidencia entre Durkheim y Freud. La última parte de esta lectura sociológica de Freud toma a Freud como simple punto de partida tanto para una interpretación derechista y conservadora de Freud como para destacar las potencialidades tevolucionatias del psicoanálisis que supieron destacar Reich, Roheim y, sobre todo, Matcuse. Matsal termina negando que sea posible hacer una crítica sociológica a Freud desde sociedades como la española, que apenas han llegado al umbral que Freud hace años cruzó. 


\section{Introducción}

Shils sostiene con razón que la sociología es la continuación -con metodología moderna- del perenne cuestionamiento del ser humano sobre los problemas fundamentales de su vida en sociedad. Las respuestas principales se hallan en las concepciones sobre la sociedad, la historia y el individuo de Ios autores que constituyen lo que Wright Mills llamara «la tradición clásica». Para Mills, Freud es uno de los grandes clásicos de la sociología. ${ }^{\mathrm{t}}$

Pero la lectura de la obta de Freud además de ser indispensable desde el punto de vista de una formación sociológico humanística, lo es también como purificación conceptual para todo individuo de nuestro tiempo que ha recibido entre los objetos de consumo cultural, subrepticiamente, un legado de freudismo maleado.

Erich Fromm (como desde otra perspectiva Marcuse) ha sabido desenmascarar el proceso de digestión del psicoanálisis freudiano por la American way of life. Popularizado, el psicoanálisis se convierte en «mensajeto de libertad sexual para la pasión del nuevo consumidor» y es «un sustituto del radicalismo en política y religión. ${ }^{2}$ En las sociedades de cultura latina como la nuestra, la influencia no es tan directa, se trata más bien, como ha señalado Castilla del Pino, de «una incorpotación cultural difusa, en modo alguno como influencia directa de la literatura psicoanalítica ni, tampoco, del psicoanálisis. Este último puede ser de importancia en la sociedad norteamericana, pero entre nosottos, por razones obvias, es todavía desdeñable». ${ }^{3}$

1. C. Wright Milds, ed., Inages of Man, The Classic Tradition in Sociological Thinking (Nueva York: Braziller, 1960), pp. 2-5.

2. Erich Fromm, Sigmund Freud's Mission (Nueva York: Blackcat 1959), pp. 118119, y Marx i Freud (Barcelona: Edicions 62, 1957), p. 156.

p. 112 .

3. Catlos Castilla del Pino, Psicoanálisis y marxismo (Madrid: Alianza, 1969), 
El pensamiento freudiano deriva entonces en uno de los elementos de la "prótesis de la personalidad», según la conocida expresión de Fisher, del hombre de la sociedad de consumo. Ello se hace quizá más evidente aun cuando este tipo de sociedad está afectada por una profunda crisis y se ve amenazada en su supervivencia como tal tipo de sociedad consumista, como le sucede actualmente a la clase media argentina.

La metamorfosis ideológica de la obra de Freud es tanto más artera por cuanto supone un total divorcio de las ideas de Freud, como producto objetivado, de la matriz ética y social donde nacieron. Porque las teorias psicoanaliticas de Freud nacen de la ética del trabajo — «la ética puritana» estereotipada por Weber- de la burguesía en su periodo de ascenso, con su énfasis dieciochesco en el "dominio de la pasión por la razón», que Freud un tanto tardia $y$ pesimistamente representa tan bien. Mientras que el énfasis en el consumo, y en el placer sexual como objeto de consumo, corresponde a una época de la burguesía instalada, satisfecba y a la defensiva.

Sezá tarea nuestra aquí encontrar lo esencial de Freud despojándole tanto del ropaje impuesto por su tiempo y su cultura como de los ulteriores atuendos echados encima por la sociedad de nuestro tiempo.

\section{El descubrimiento de nuevas zonas de realidad y su tratamiento}

La ciencia ha avanzado a través de los tiempos, como una vez escribiera Parsons, como pequeños focos de luz en una inmensa oscuridad. Que esa inmensa oscuridad pueda ser algún día totalmente iluminada y dominada por el hombre es la materia de la creencia que conocemos por cientismo o cientificismo, creencia con la que, por cierto, Freud comulgaba. Entretanto no llegue ese saber final, total, la ciencia avanzará según la conocida imagen de Santayana: "como un ejército de hormigas». Este avance de tanto en tanto cruza un umbral y abre una nueva porción de realidad arrancada a otros saberes como el folkiore y el misticismo. Eso es lo más importante de Freud: que ya no se puede volver atrás del umbral cruzado por él; que ya no se puede creer o sostener ciertas ideas sobre la psique, quue quedaron atrás arrumbadas en el desván de los trastos viejos del anactonismo y el mandarinato cultural. Como dice Erik Erikson: «Freud creó su teoría irrumpiendo a través de la hipocresía y el olvido artificial de su época que relegaba a todas las "funciones inferiores" del hombre al dominio de la vergüenza, del ingenio de dudosa especie y de la imaginación mórbida.»4

4. Erik H. Erikson, Intancia y sociedad (Buenos Aires, Horme, 1966), p. 51. 
El propio Freud en una página famosa de sus conferencias introductorias se ha mostrado bien consciente de sus descubrimientos cuando considera al psicoanálisis como la tercera revolución después de las de Copérnico y Darwin. Pero la jactancia del descubrimiento viene acompañada por el toque de pesimismo humanista típicamente freudiano en cuanto que considera a estas revoluciones como «mortificaciones» de la megalomanía humana y una decepción para «el ingenuo egoísmo de la humanidad». Sólo faltaba la investigación psicológica moderna para demostrar que el ser humano no sólo no es el centro del universo ni tiene un puesto privilegiado en el orden de la creación, sino que «ni siquiera es dueño y señor de su propia casa». ${ }^{5}$

Ahora bien, ¿cuáles son las áreas claves de la persona humana sobre las que Freud construye sus teorías? A mi juicio una clasificación por orden de importancia tendría que colocar en un primer grupo a la sexualidad infantil, el continuo normal-anormal, el inconsciente, los sueños $y$, por último pero no menos importante, la esfera de la sexualidad y los afectos.

Contra la repulsa general. y la indignación de sus coetáneos, como él mismo relata en su Autobiografía, Freud mantuvo «que la función sexual se inicia con la vida misma y se manifiesta ya en la infancia por importantísimos fenómenos». «Ningún descubrimiento psicoanalítico -escribe un tanto jactanciosamente Freud- puede ser demostrado tan fácil y completamente como esto. ${ }^{6}$ Freud saca así a la niñez de la tierra de nadie donde la había dejado la ciencia o de la gratuita «inocencia» atribuida hasta la pubertad al niño por: la literatura piadosa. Contra estas creencias generalizadas Freud, en 1905, en sus Tres ensayos sobre una teoria sexual, defenderá con escándalo su tesis de la complejidad sexual de la naturaleza infantil y su carácter "polimórficamente perverso».

Otro terreno en el que Freud se enfrenta con el saber de su tiempo es al oponerse a la identidad de lo psíquico y lo consciente, como era lugar común en la psicología prefreudiana. Incluso, en algunos de sus escritos, llega a sostener que «la diferenciación de lo psíquico en consciente e inconsciente es la premisa fundamental del psicoanálisis», ${ }^{7}$ afirmación que repetirá años adelante Fromm al escribir que «el inconsciente es el descubrimiento fundamental de Freud». Este hallazgo de tanta importancia terapéutica, tiene también mucha relación con el tratamiento de lo psíquicamente anormal como algo de diferencia sólo relativa con la salud y lo

5. Sigmund Freud, Introducción al psicoanálisis (Madrid: Alianza, 1969), p. 308.

6. Sigmund Freud, Autobiografía (Madrid: Alianza, 1973), p. 46.

7. Sigmund Freud, El yo y el ello (Madrid: Alianza, 1973), p. 8. 
normal. «Una diferencia de orden cuantitativo y no cualitativo», como mantendrá Freud en contra de la práctica médica y de la prevención social de la locura en su tiempo.

De otro de sus hallazgos fundamentales, la interpretación de los sueños, Freud se sentitá orgulioso hasta la última etapa de su vida por «habet conquistado un dominio nuevo a las ciencias populares y a la místicas. ${ }^{8}$ Pero a diferencia de lo que sucede con la niffez o la anotmalidad, no se opone a ellas, ya que las considera "cercanas a la verdad». A to que se opone es a la medicina de su tiempo, que consideraba al sueño «un proceso físico inútil cuando no patológico». Para Freud, en cambio, Ia «luminosidad de su súbito descubrimiento», como él nos dice, consiste en que el sueño «no es desatinado ni absurdo..., es un acabado fenómeno psíquico, y precisamente una realización de deseos».?

Es una ironía que haya tenido que ser Freud, este «judío puritano», quien haya llevado bajo el foco de la investigación científica a toda la zona de lo humano conexo con el sexo y rescatarla de las oscaridades mitológicas en las que se to tenía relegado. Es indudable que Freud convierte el sexo en una especie de deus ex macbina de su psicología. Como por ejemplo en el caso Dora, donde afirma que «la sexualidad es la clave de la psiconeurosis y las neurosis. Nadie que no lo reconozca así llegará jamás a solucionarlo». ${ }^{10}$ Pero más adelante lo sexual biológicamente determinado viene a integrarse en el concepto mucho más amplio de la líbido que se acerca más a un área difusa de lo afectivo o "catártico" (como to había llamado Breuer $\mathrm{y}$, tiempo después, to denominará Parsons). No es que Freud desconociera desde temprano la influencia perturbadora de otros complejos como los profesionales, to que sucede es que el esfuerzo por poner a la luz la sexualidad en toda su complejidad bermafrodítica, basta entonces tan desconocida, le lleva a una concentración causal en lo sexual, lo que por otra parte estaba en contradicción con su convicción en la pluralidad causal de los tenómenos bumanos." Erikson ha sosotenido muy bien la estrategia metodológica yacente tras esa acentuación en lo sexual de Freud, al decir que "sería mejor llamar sexual a demasiadas cosas, que a muy pocas, para después modificar cuidadosamente la hipótesis así in-

8. Sigmund Freud, «Nuevas decciones introductorias al psicoanálisis» en Obras Completas, tomo VIII (Madrid: Biblioteca Nueva, 1974), p. 3102.

9. Sigmund Fteud, La interpretación de los sueños (Madrid: Alianza, 1975), tomo I, p. 189.

10. Sigmund Freud, "Análisis fragmentatio de una historia» en Historiales Clinicos (Butenos Aires: Editorial Americana, 1943), p. 134.

11. Véase, por ejemplo, Sigmund Freud, Psicopatología de la vida cotidiana (Madrid: Alianza, 1972), p. 52. 
troducida». ${ }^{22}$ Al fin y al cabo, no otra fue la estrategia de otros descubridores, como Marx y Engels; este último ha reconocido en su correspondencia, que tuvieron que hacer hincapié en el aspecto económico, que era el principio cardinal que ellos afirmaron, aun con descuido de otros factores y de su autonomia. ${ }^{13}$

Rof Carballo, en el prólogo a la última edición de las obtas completas, sugiere, frente a una excesiva tendencia a la sociologización del pensamiento freudiano, que la obra del médico vienés snace de la clínica, esto es, de la observación de los enfermos». Es decir, Freud descubrió nuevos niveles de la persona en el esfuerzo por curar ciertas anormalidades de la vida psíquica hasta entonces descuidadas, particulatmente la neurosis. Todos los conceptos anteriormente señalados como la sexualidad infantil, la anormalidad, el inconsciente o los sueños, están estrechamente vinculados al tratamiento psicoanalítico. Así, no solo se descubre un nivel de realidad, sino que se trata de transformarla.

El método psicoanalítico de Freud nace en pugna con lo que él llama «los hábitos mentales de la Medicina» en el sentido de que sólo se buscaban las causas anatómicas de lo psíquico. Toda la obra de Freud, por el contratio, estazá dirigida a la búsqueda de las causas psíquicas de lo orgánico, los "motivos de la enfermedad», como escribe en cierta ocasión. ${ }^{14}$ Para darse idea de lo revolucionario de la posición de Freud, hay que recordar que en la Viena de su tiempo las autoridades médicas solían diagnosticar la neurastenia como tumo: cerebral.

No es éste el lugar para exponer la terapéutica psicoanalítica. Baste recordar que se trata de pasar lo inconsciente a lo consciente y que Freud, a diferencia de otros colegas psicoanalistas, sostendrá hasta el final que lo inconsciente es fundamentalmente to infantil. Es, pues, un «método histórico» en cuanto a que si bien se basa en los datos médicos los interpreta como una función de la experiencia individual pasada. El psicoanalista, mediante la transferencia, debe vencer los mecanismos de defensa que impiden el análisis y fortalecer el yo en su difícil rol de «monarca constitucional» entre las fuerzas represoras del super-ego y el instintivismo.

El problema del tratamiento psicoanalítico nos lleva como última cuestión al de su resultado. Freud mismo, que en strs primeras exposiciones

12. Erik Erikson, «Crisis psicoanalítica de Sigmund Freud» en T. W. Adorno y Waiter Dirks (eds.), Freud en la actualidad (Batcelona: Barral, 1971), p. 42.

13. Engels a J. Bloch y F. Mehring en C. Marx y F. Engels, Obras Escogidas (Moscú: Lenguas extranjeras), tomo II, pp. 522-530.

14. Véanse, entre otros textos, S. Freud: Introducción al psicoanálisis, op. cit., p. 15; Interpretación de los sueños, op. cit., p. 108; «Análisis fragmentatio de una historias, op. cit., p. 134. 
había definido al neurótico curado como «el que hubiera podido ser independientemente del tratamiento en condiciones más favorables», ${ }^{15}$ se vuelve más caviloso al final de su vida, cuando dice que «el análisis logra a veces eliminar la infuencia de un aumento del instinto, pero no invariablemente», y que es mejor hablat de un «análisis incompleto» que de un "análisis inacabado». ${ }^{16}$

Desde Freud las aguas han corrido mucho bajo los puentes de la terapia psicoanalítica, y los analistas siguen ahora caminos muy diversos. Peto Freud sigue siendo lo que fue: un punto de partida. Y como en tiempos de Freud mismo su terapia, el psicoanálisis, sigue siendo más una averida de claridad intelectual que un método seguro de curar.

\section{La teoria social de Freud y su influencia en sociología}

¿Cuál ha sido la influencia de los conceptos e ideas freudianas en sociología? ¿Existe realmente una teotía o teorías sociales de Freud fuera de su experiencia clínica de lo individual? ¿Cuál ha sido la respuesta de la sociología académica a la penetración teórica freudiana?

Demostrar que los conceptos freudianos han penetrado ampliamente en las ciencias sociales sería hacer lo que Sorokin Ilamaba «una penosa elaboración de lo evidente». Los conceptos freudianos axiales del yo-superyo y el ello invaden la literatura sociológica como toda nuestra cultura; las tipologías libidinales de Freud y sus discípulos están en la base de cualquier tipología que inserte lo individual en lo social; las telaciones interpersonales no son ya explicables sin la explicación de los roles sexuales que Freud reveló. En el campo de las técnicas de investigación sociológica, la metodología psicoanalítica ha influido directamente en la entrevista en profundidad y en la entrevista no focalizada, tal como Merton la formalizara luego. Con carácter más general tras el método de casos están los casos clínicos del fundador del psicoanálisis.

Pero aún hay más: el énfasis en lo personal, en lo biográfico caló hondo en los grandes sociólogos disidentes norteamericanos desde Mills a Gouldner. Mills afirma una y otra vez que el trabajo sociológico que no combina biografía, historia y sociedad no ha terminado su jornada intelectual, mientras que Gouldner, recientemente, en su embate contra el «objetivismo» sociológico ha proseguido en la misma línea sosteniendo

15. S. Freud, Introducción al psicoanálisis, op. cit., p. 465.

16. Véase S. Freud, «Análisis terminable e interminable», Obras Completas, op. cit, tomo $\mathrm{XX}$. 
que el compromiso del sociólogo significa que pata la teoría sociológica es de especial importancia «la infraestructura personal del teórico: sus presunciones básicas, sus sentimientos y las cosas que él personalmente define como reales». ${ }^{.7}$

Pero además de esa difusa influencia de los conceptos y metodología freudiana en las ciencias sociales, y la sociología en particular, hay especialidades como la sociología del conocimiento en que Freud se coloca junto a los fundadores. La distinción entre manifiesto y latente, que Freud enuncia por primera vez en su Interpretación de los sueños (y que Merton incorpora luego a la teoría estructural-funcionalista) se transforma en una de las piedras angulares de la visión sociológica del conocimiento. La idea de una realidad «de fachada» a la que se refiere Freud en su trabajo sobre los sueños, deviene en la proposición central de la perspectiva humanística de Peter Berger, por ejemplo, para quien «la perspectiva sociológica implica un proceso de comprensión a través de las fachadas de las estructuras sociales». ${ }^{18}$

Freud no toma las ideas ni el conocimiento a prima facie. Los afectos entran en escena; para Freud «los juicios estimativos de los hombres son infaliblemente orientados por sus deseos de alcanzar la felicidad, constituryendo, pues, tentativas destinadas a fundamentar sus ilusiones con argumentos», dice en El malestar de la cultura. ${ }^{19} \mathrm{Y}$ ya muchos años antes en uno de sus casos más famosos, «El hombre de las ratas», Freud había hecho notar que «no estamos acostumbrados a sentir en nosotros afectos intensos sin contenido ideológico, y por tanto, cuando tal contenido nos falta, echamos mano de otro cualquiera adecuado, como subrogado". ${ }^{20}$ Esta perspectiva es común a Marx y Freud y por ello a ambos los llama Ricoeur «maestros de la sospecha». Como escribe Fromm acertadamente, «Marx créa que la realidad básica es la estructura económica de la sociedad; Freud, en cambio, creía que lo era la organización libidinosa del individuo. Pero ambos sentían la misma aversión implacable por los clichés, las ideas, las racionalizaciones y las ideologías que llenan Ia mente de los hombres y que constituyen la base de aquello que toman erróneamente por realidad $\gg .21$

Otro campo en el que Freud se constituye en un must es en sociologia de la familia. Aunque es inadmisible la sustitución que Freud velis nolis

17. Aivin Gouldner, For Sociology (Nuteva York: Basic Books, 1973), p. 95 .

18. Peter Berger, Introducción a la Sociología (México: Limusa-Wiley, 1967), p. 51.

19. S. Freud, «El malestar en la cultura» en Obras Completas (Editorial Americana), op. cit., tomo XIX, p. 112.

20. S. Freud, Historiales Clinicos, op. cit., p. 29.

21. E. Fromm, Marx i Freud, op. cil., p. 20. 
practica de la sociedad global por la unidad familiar, es también indudable que la relación entre «cultura y personalidad», como dicen los antropólogos, no se puede entender sin estudiar lo que en los historiales clínicos de Freud figura como el «ambiente familiar de la niñez». $X$ dentro de esa matriz deben situarse los roles sexuales sin los que no se entiende la formación de la personalidad básica. Por otra parte, en Freud se encuentra un análisis crítico de las consecuencias sociales de la «doble moral» sexual practicada por la burguesía y las consecuencias neuróticas de la vida sexual matrimonial de su tiempo. ${ }^{22}$ Es evidente que todos los planteamientos posteriores en el campo de la sociología familiar han absorbido la crítica a la moral victoriana de Fteud, bastante tímida por cierto, pero con toda la fuerza de la evidencia a su alcance.

\section{La antropologia social de Freud}

La teotía social y antropológica es, a mi juicio, el punto más débil de la obra de Freud. Pero no me parece correcto despacharla con la acusación de su rasgo más saliente, que es su evidente «psicologismo». A obra de tal magnitud y profusión como la freudiana cabe muy bien la advertencia que hace Hostadter sobre el gran historiador norteamericano Frederik Jackson Turner: «El procedimiento más válido con un pensador de esta clase es no tomarse a la ligera sus fallos marginales, sino rescatar cuanto sea viable separándolo de lo que está equivocado.» ${ }^{23}$

La teoría social de Freud no se agota con el evidente «psicologismo» del que Freud reiteradamente hace gala. En la psicología de las masas y análisis del yo, Freud sostiene desde la primera página que «la psicología individual es al mismo tiempo, y desde un principio, social», con lo que Freud quiere decir casi exactamente lo contrario, es decir, que la psicología social es una parte de la psicología individual, pues los actos sociales no son más que una clase de actos psicológicos individuales por contraposición a los actos narcisistas. La eoposición entre actos anímicos sociales y narcisistas cae dentro de la psicología individual y no justifica una diferenciación entre ésta y la psicología social o colectiva», escribe inequívocamente Freud. ${ }^{24}$ Así, literalmente, lo toman sus más ortodoxos seguidores, como Erikson, para quien «la historia de la humanidad es un metabolismo gigan-

22. Véase S. Freud, «La moral sexual cultural y la nerviosidad moderna» en Ensayos sobre la vida sexual y la teoria de la neurosis (Mad́rid: Alianza, 1972).

23. Richard Hofstadter, The Progressive Historians (Nueva York: Knopp, 1968), p. 119.

24. S. Freud, Psicología de las mosas (Madrid: Alianza, 1974), pp. 9-10. 
tesco de cicios de vida individual», o su fel biógrafo Jones recordando que su maestro le dijo en alguna ocasión que la sociología «no puede ser otra cosa que una psicología aplicadas. ${ }^{25} \mathrm{La}$ única escapatoria posible a esta actitud freudiana derivada de su «apoliticismo» general sería la de que un libro como La psicología de las masas no fue escrito, como dice Kris, como un tratado de psicología social, sino pata aumentar la claridad del modelo estructural de la personalidad sobre el que Freud estaba trabajando en aquella época. ${ }^{26}$

Toda la producción intelectual de Freud está plagada de psicologismo, o «solipsismo», como gusta llamarle Castilla del Pino. El problema de la psicología colectiva se reduce a hallat en los individuos las huellas mnemónicas de su herencia arcaica, lo que permitiria tratar a los pueblos igual que a los neuróticos; ${ }^{27}$ el antisemitismo tiene su raíz más profunda en el complejo de castración que Freud descubre en el caso de Juanito, ${ }^{28}$ la ne cesidad inperiosa de autoridad que sienten los seres humanos no es otra cosa que la añoranza del padre que cada uno de nosotros alimenta desde su niñez; ${ }^{29}$ el «egotismo ilimitado» y la tendencia destructora del criminal son manifestaciones de desamor; ${ }^{30}$ las culturas se tornan neuróticas. ${ }^{3 t}$

El palmario psicologismo de Freud puede llevar a conclusiones apresuradas como la de Roger Bastide, para quien hay una oposición fundamental entre la sociología de Durkheim y el psicoanálisis de Freud: «El freudismo parte del primado de la líbido, única fuerza creadora, en definitiva, y el durkheimismo del primado de la institución. $\otimes^{32}$

Análisis más matizados como el de un trabajo aún inédito de Jesús M. de Miguel ponen en evidencia ciertas coincidencias entre ambos autores más allá de su propia intención y de las escasas y poco ilustradoras teferencias explícitas del uno al otro. En primer lugar, están las coincidencias más inconsecuentes con todo el argumento de sus respectivas teorías, como la noción de «conciencia colectiva» en Durkheim o el «alma o inconsciente colectivo» en Freud, debidas sin duda a la influencia recibida por ambos

25. E. Erikson, Infancia y sociedad, op. cit, p. 12, y Enest Jones, Vida y Obra de S. Freud (Barcelona: Anagratna), tomo III, p. 181.

26. Enest Kris, «Sorne problems of war propaganda» en Psycboanalytic Quterly, vol. XII (1943), p. 394.

27. S. Freud, «Moisés y la teligión monoteista» en Escrilos sobre judaísmo y antisemitismo (Madrid: Alianza, 1974), p. 143.

28. S. Freud, Historiales clínicos, op. cit., tomo I, p. 175.

29. S. Freud, «Moisés...», op. cit., p. 157.

30. S. Freud, «Dostoievski y el parricidio» en Psicoanálisis del arte (Madrid: Alianza, 1973), p. 214.

31. S. Freud, El malestar en la cultura, op. cit., p. 111.

32. Roger Bastide, Sociología y psicoanálisis (Buenos Aires: Fabril, 1966), p. 31. 
autores pertenecientes a la tradición cultural idealista alemana, como Wundt. ${ }^{33} \mathrm{Hay}$, sin embargo, algunas coincidencias derivadas de posturas más reiteradas a todo lo largo del pensamiento freudiano. Me refiero al «funcionalismo» de muchos de los análisis de Freud que lo colocan en la misma matriz intelectual que la del gran maestro coetáneo de funcionalismo que fue Durkheim.

Ello es patente en el análisis freudiano de la religión. La religión no es sólo para Freud la representación en el hombre de «la creación del mundo a la manera de su propia génesis», las ideas religiosas son también «ilusiones, realizaciones de los deseos más antiguos, intensos y apremiantes de la Humanidad», con Io cual la religión queda teducida a una ideología, o si se quiere, en terminología freudiana, a una «neurosis». ${ }^{34}$

Pero hay más, y esto lo acerca a Durkheim y a las teorías de los pensadores contrartevolucionarios que están tras él. La religión cumple lo que Ilama Lévy una «eufunción» social. «La religión ha cumplido -escribe Freud en El bombre de los lobos-m cuanto le corresponde en la educación del individuo... La religión cumplió así su obra en el pequeño descarriado mediante una mezcla de satisfacción, sublimación y apartamiento de lo sexual por medio de procesos puramente espirituales y facilitando, como a todo creyente, una relación con Ia colectividad social. $\$^{35}$ Pero la teligión, que «ha prestado grandes servicios a la civilización humana», no es bastante para dominar los instintos sociales, escribirá años adelante en El porvenir de una ilusión. En este terreno y en otros muchos la aspiración a una secularización de la religión, que es la ambición de los pensadores postrevolucionarios de Comte en adelante, es común tanto a Durkheim como a Freud. La ascética del cristianismo, para Freud, «creó para el amor valoraciones psíquicas que la antigüedad pagana no había podido ofrendarle jamás», ${ }^{36}$ que es precisamente lo que Chesterton con su particular ironía Llamaba «la buena nueva del pecado original». Lo que Freud trató tanto como Comte o Durkheim es de «cambiar de zumbo» y secularizar la religión. Entonces, escribe, «dejaremos de atribuir a Dios nuestras propias voluntades, contentándonos con el fundamento social, y renunciaremos desde luego a semejante transfiguración cultural, pero evitándonos también sus peligros».,36

Junto al psicologismo conspicuo y al funcionalismo latente, destaca en

33. S. Freud, Totem y tabú, Obras completas (Buenos Aires: Editorial Americana, 1943), pp. 12-50.

34. S. Freud, «El porvenir de una ilusión», Obras Completas (Madrid: Editorial Nueva, 1974), tomo VIII.

35. S. Freud, Historiales clinicos, op. cit., tomo II, pp. 311-312.

36. S. Freud, El porventir de uno ilusión, op. cit., p. 2983. 
la teoria social y antropológica de Freud la herencia darwiniana con todo su legado evolucionista, en la misma línea que Comte, Spencer o Durkheim.

La sociología, mejor dicho, la antropología de Freud pertenece por completo al evolucionismo y está particularmente influenciada por Frazer. Freud, como él mismo confiesa en diversas oportunidades, estaba dema. siado dedicado a afianzar sus hallazgos fundamentales en el campo de la psique y el método psicoanalítico como para poder preocuparse del estado de otras ciencias. De ahí el anacronismo de sus teorías antropológicas y sociológicas basadas en Frazer o Le Bon cuando ya estaban en escena Durkheim o Malinowski.

Del funcionalismo se puede hacer una severa crítica y ha sido desenmascarado una y otra vez por sus conexiones ideológicas. Pero otra cosa es tanto lo prefuncionalista como lo premodeno y lo preburgués. La teorfa antropológica de Freud es prefuncionalista cuando ya los antropólogos funcionalistas como Radcliffe-Brown y Malinowski habían asestado un golpe mortal al evolucionismo antropológico. Cualesquiera sean los fallos de la antropología funcionalista, no es posible ya volver al evolucionismo con su establecimiento de grandes etapas históricas para toda la humanidad, como un ordenado curriculum académico que todas las socie. dades tienen que pasar para licenciarse en civilización blanca y occidental.

La teoría antropológica de Freud encaja rigurosamente en la tradición del evolucionismo positivista expresado, como en el siguiente texto de Totem y tabú en su prístina expresión idealista comteana. «Si hemos de dar fe a los investigadores - escribe Freud-, la humanidad habría conocido sucesivamente, a través de los tiempos, tres de estos sistemas intelectuales, tres grandes concepciones del universo: la concepción animista (mitológica), Ia religiosa y la científica.» ${ }^{37} \mathrm{~A}$ esta posición claramente evolucionista se agrega además el psicologismo característico de la teoría freudiana al establecer un paralelo entre el desarrollo de la concepción humana del mundo y el de la líbido individual. «Hallamos entonces [dice Freud] que tanto temporalmente como por su contenido, corresponden la fase animista al narcisismo, la fase religiosa al estadio de objetivación carac. terizado por la fijación de la líbido a los padres, y la fase científica a aquel estadio de madurez en que el individuo renuncia al principio del placer y, subordinándose a la realidad, busca su objeto en el mundo exterior. $\rangle^{38}$

La «treta favorita» de la teoría evolucionista es la búsqueda de los orígenes, que «consiste [como dice Malinowski] en que esta o aquella

37. S. Frewd, Totem y tabi, op. cit., p. 108.

38. Ibidem, p. 124. 
tribu o tipo humano son las características supervivencias primitivas de la humanidad originarias. ${ }^{39}$ Esta treta evolucionista es transportada por Freud al terreno psicológico, donde le parece incuestionable la «conservación de lo primitivon junto a lo evolucionado y es redondeada en su estudio de Ia memoria y la vida onírica, donde nada de aquello que hemos poseído alguna vez se pierde por completo. Freud sostiene la identidad de las características anímicas de lo primitivo no sólo en la vida de los pueblos salvajes supervivientes, sino en la vida anímica individual tanto del niño como del neurótico. ${ }^{40} \mathrm{Y}$ esta hipótesis de la continuidad de la vida psíquica, de la herencia de ciertas disposiciones psíquicas, es crucial para entender la psicología de los pueblos, como la llama Freud.

El concepto de residuo cultural, en el sentido del evolucionismo antropológico, y no en el de Pareto, es usado reiteradamente por Freud. Así, por ejemplo, el incesto, que tanto para él como para Engels, que bebió en fuentes muy similares, es un invento del período del matrimonio grupal; - el período de latencia sexual que sucede a la primera infancia, que es también un residuo de la historia primitiva; e incluso el origen de la represión sexual, que «residiría en los mecanismos de defensa orgánica que la nueva forma de vida adquirida por la bipedestación dirige contra la precedente existencia animals. ${ }^{41}$

La clave del arco de toda la antropología social freudiana es sin duda su hipótesis de la comida totémica que explica la continuidad del estado primitivo de la sociedad humana en el presente. Fue expuesta por Freud en toda su amplitud en Totem y tabú y referida a lo latgo de toda su obra. ${ }^{42}$ Freud no ignotaba que su hipótesis podía parecer fantástica, pero para él representaba la ventaja «de reducir a una unidad insospechada series de fenómenos hasta ahora inconexos». La hipótesis de Freud es que en la horda primitiva el padre tiránico expulso a sus hijos y éstos se reunieron, lo mataron y devoraron su cadáver; ello se recuerda aún en las comidas totérnicas de ciertos pueblos primitivos. Pero lo más importante para todo el género humano es que a consecuencia de ese proceso afectivo surgió el remordimiento y nació la conciencia de culpabilidad que es el origen de la moral y la religión. De ahí entonces que ese asesinato primitivo sea «el magno suceso con el que se inicia la civilización y que no ba dejado de atormentat desde entonces a la Humanidad".

Creo que si la ciencia, como repetía siempre Wilbert Moore, se carac-

39. B. Malinowski, Una teoría cientifica de la cultura (Barcelona: EDHASA, 1970), p. 215.

40. S. Frend, Psicología de las masas, op. cit., p. 18.

41. S. Freud, El malestar de la cultura, op. cit., p. 64 .

42. S. Freud, Totem y tabú, op. cit., particularmente pp. 192.196. 
teriza por su vocación por la verificación por los datos, la hipótesis de Totem y tabú dice mucho del «arte expresivo» de Freud y de su imaginación, pero favorece poco a su confeso cientismo. Una hipótesis, por muy fructifera que pueda ser para la explicación de un fenómeno, pero para la que es imposible ni contemporáneamente ni en el futuro adquirir exactitud ni certidumbre, como el propio Freud reconoce, cae, como las denás brillantes fantasías evolucionistas, dentro de la crítica de Malinowski: «Todas esas sugestiones expresan más bien la fertilidad de la imaginación de los antropólogos, que son pruebas o demostraciones sólidas», y, lo que es más inútil, no cuenta para entender el funcionamiento de las sociedades actuales.

Las edulcoraciones a esta inescapable crítica, como la de Roazen, que dice que era una «ficción romántica», «una especie de contrato social» o el énfasis en su «función explicativa» o su marginalidad respecto a la preocupación freudiana central por la estructura de la personalidad, nada quitan ni ponen a la esencial acientificidad de su teoría antropológica. Algo que no se puede probar ahora ni se podrá verificar nunca, puede ser britlante, genial y esclarecedor, pero no cabe dentro de la lógica científica. Como dice Marion Levy: la ciencia no exige que todo sea verificado, pero tiene que ser por lo menos «verificable».

\section{Crítica sociologica}

La crítica de gran parte de la sociología académica de las teorías sociológicas de Freud han apuntado, a bulto, a su «biologismo» y un poco más aftnadamente, como Bastide, a su postulado de «identidad del espíritu humano»".

Esto último toca ya al nódulo de la cuestión. Es decir, que el aspecto psicologista de las teorías sociológicas y antropológicas de Freud está en oposición a la corriente de la tradición sociológica dominante que ha construido una imagen totalmente opuesta del hombre que en su caricatura es el «hombre sobresocializado», como lo llama Dennis Wrong. Desde Mead hasta Goffman la imagen predominante del hombre de la sociología académica es la de un «haz de roles», un «personaje» en el lenguaje teatral de Goffman.

Un texto, elegido entre muchos, muestra lo que es esta imagen predominante en sociología. El siguiente es de Gerth y Mills en su Carácter y estructura social:

El hombre como persona es una creación histótica y se lo pue- 
de comprender con mayor facilidad en términos de los roles que desempeña e incorpora. Estos roles están limitados por el tipo de instituciones sociales en las cuales nace y en las cuales madura como adulto. Su memoria, su sentido del tiempo y del espacio, su percepción, sus motivos, su concepción de sí mismo [...] sus funciones psicológicas están moldeadas y dirigidas por la configuración específica de roles que incorpora de su sociedad.

Posiblemente el más importante de estos rasgos del hombre es la imagen de sí mismo, su idea de qué tipo de persona es. Esta experiencia de sí mismo es una experiencia crucialmente interpersonal. Su organización básica se refleja de las personas circundantes a cuyas aprobaciones y críticas presta atención. ${ }^{43}$

Nada más opuesto que esta «historiciỏad» a la historicidad estrictamente individual del grueso de la psicología freudiana. Si en Freud la psicología social es, en ulttimo término, psicología individual, en la tradición sociológica se invierten completamente los papeles y la psicología individual es, en último término, mera psicología social.

No es extraño, entonces, que los psicoanalistas revisionistas, como Fromm, muy influidos por la sociología norteamericana, hayan tomado literalmente esta inversión de términos. "Creemos [escribe Fromm en $E l$ miedo a la libertad] que el hombre es primariamente un ser social y no, como lo supone Freud, autosuficiente, y sólo en segundo lugar necesitado de mantener relaciones con los demás con el fin de satisfacer sus exigencias instintivas. En este sentido creemos que la psicología individual es esencialmente psicología social o, para emplear el término de Sullivan, «psicolo. gía de las relaciones interpersonales».4 Esta preeminencia de lo social de la psicología frommiana le llevará al concepto luego cuestionado por Marcuse del «carácter social» que mutatis mutandis, como buena parte de la teoría sociológica dominante, viene a sustituir al concepto de estructura social estratificada en clases. El carácter social es para Fromm «el núcleo de la estructura caracterológica compartido por la mayoría de los miem. bros de una misma cultura en contraposición al carácter individual, que diferencia a las personas pertenecientes a una misma cultura». ${ }^{45}$

43. H. Gerth y C. W. Mills, Carácter y estructura social (Buenos Aires: Paidós, 1961), p. 32.

44. Erich Fromm, El miedo a la libertad (Buenos Aires: Paidós, 1961), p. 329.

45. E. Fromm, Marx i Freud, op. cit, p. 92. 


\section{La cosmovisión freudiana}

Algunos autores anglosajones han querido separar en el tiempo la obra de Freud poniendo como frontera el año 19:18, en el que la teoría científica de Freud empezaría a ser sustituida por «especulaciones culturales». Me parece un intento útil. Pues, como en casi todos los científicos, sus hallazgos empíricos se hallan entremezclados con su ideología -el «mapa moral y cognitivo del mundo», como la llama Shils- y las motivaciones personales de su descubridor. La separación de ciencia e ideología es una asíntota indeclinable del saber científico, pero no es proclamable por fiat. En Freud, como en casi todos los grandes descubridores de una nueva zona de realidad humana y a pesar de todas sus declaraciones expresas contra la elaboración de sistemas univetsales, se observa la tentación de convertir sus descubrimientos en «piedra filosofal». Recuérdese que Totem y tabu, obra en la que se halla el meollo de las especulaciones culturales de Freud, está escrita en 1911, año en que de ninguna manera se puede hablar de un Freud viejo.

La Weltanscbaunng freudiana se halla formada por diversos componentes no totalmente conciliabies. Los más destacados y a los que nos teferiremos a continuación son el cientismo, el racionalismo y el vitalismo pesimista.

En Freud están manifestamente todos los elementos de lo que él mismo llama la concepción cientifica del universo. El psicoanálisis, como toda ciencia, es provisional y to caben últimas causas ni últimas fuentes de explicación, sino una multicaussalidad derivada de la insuperable complejidad del suceder. El psicoanálisis, como el trozo de ciencia que Freud quiete que sea, se desarrolla según el modelo de la ciencia natural, que es lo que en definitiva aspira a ser. «Ell eđ̉ificio teórico del psicoanálisis creado por nosotros [dice Freud] no es en realidad sino una superestructura que habremos de sentar algún día sobre una firme base orgánica. ${ }^{46} \mathrm{O}$ sea que su modelo final no es otro, como el de Comte o Spencer, que la biología que fue el paradigma de las ciencias sociales decirnonónicas.

Hacer ciencia no es en Freud, ciertamente, sólo aséptico empirismo, sino que se remata con una creencia intolerante. Sostiene Freud en sus últimas «Nuevas lecciones sobre el psicoanálisis»:

Es inadmisible decir que la ciencia es un único sector de la actividad del espíritu humano, y la religión y la filosofía otros

46. S. Freud, Introducción al psicoanálisis, op. cit., p. 417. 
equivalentes por lo menos, en los cuales no tiene por qué intervenir la ciencia; que todos aspiran por igual a la verdad y que cada hombre puede elegir libremente de donde extraer sus convicciones y donde poner su fe. Tal distinción pasa por muy distinguida, tolerante, comprensiva y libre de angostos prejuicios. Desgraciadamente no es sustentable; participa de toda la nocividad de una concepción del universo completamente anticientífica y equivale prácticamente a ella. Lo cierto es que la verdad no puede ser tolerante, que tho admite transacciones ni restricciones, y que la investigación considera como dominio propio todos los sectores de la actividad humana y tiene que mostrarse implacablemente crítica crrando otro poder quiere apropiarse parte de ellos. ${ }^{47}$

Pero, ¿de dónde nace esta seguridad en la omnipotencia de la ciencia? Sin duda de la filosofía de la Ilustración y su pretensión de destruir y reemplazar críticamente a la concepción religiosa del universo. En eso consiste la secularización que es la política intelectual de los pbilosophes y que heredan la filosofía y la ciencia positivista del siglo XIX. Es una concepción exclusiva que no acepta la arbitrariedad en nada y que se rebela, como el propio Freud, contra la misma posibilidad de emocionarse. La civilización de la ciencia queda así plantada en las antípodas del estado de naturaleza, como en lo individual lo están las tendencias sociales frente a las tendencias sexuales. Es una civilización que requiere de la ascética del trabajo y de la sublimación, pues, como escribe Freud, «suprimida la civilización, lo que queda es el estado de naturaleza, mucho más difícil de soportar».48 Todo lo demás queda al margen como una categoría residual: el arte, la emoción, el placer sexual.

Fromm ha captado muy bien este aspecto de la cosmovisión freudiana como propia de un reformador liberal que quería afianzar la conquista racionalista de la pasión por la razón mediante la rectificación de la concepción ingenuamente intelectualista de los racionalistas dieciochescos. Escribe Fromm:

Su objetivo tiene sus raíces en el protestantismo y en la flosofía de la Ilustración, en la fllosofía de Espinosa y en la religión de la Razón, pero en Freud asume una forma que le es específica. Hasta Freud se habían intentado dominar los afectos irracionales

47. S. Freud, «Nuevas tecciones introductorias al psicoanálisis», op. cit., vol. VII, p. 3192.

48. S. Freud, El porvenir de una ilusión, op. cit., vol. VIII, p. 2967. 
del hombre por la razón, sin conocerlos, o mejor sin conocer sus fuentes profundas. Freud, que creía que había descubierto esas fuentes en los vínculos libidinosos y en los complicados mecanismos de represión, sublimación, formación de síntomas, etc., creía que ahora, por primera vez, el sueño secular de autocontrol y racionalidad podia ser realizado. 4

Esta firme creencia de Freud es sólo parte de su cosmovisión, como veremos en seguida; así como las imprevisibles derivaciones de lo que él -en su reformismo racionalista- descartó somo hallazgos marginales.

En la cosmovisión freudiana, junto a ese ingtediente reiteradamente confeso de cientismo, corte un tanto subrepticiamente una fllosofía de tipo vitalista o existencialista, si se la quiete llamar así, como si no la hubiese podido evitar. Por eso Freud reconoce con cierta repugnancia sus "amplias coincidencias» con Schopenbauer y también con Nietzche.

Para Freud toda la actividad psíquica del hombre está dirigida a procurarnos placer y evitar el displacer. Eso es lo que quiere expresar en uel principio del placer que rige la vida». La aspiración última del ser humano es la felicidad individual. Pero a esta concepción placentera de la felicidad todo se le opone, y entonces sólo cabe la fuga a la neutosis, el trabajo libremente elegido $o$, en forma más general, la estrategia del comerciante prudente. Bajo la presión de tales motivos de sufrimiento el hombre suele rebajar sus pretensiones de felicidad; el evitar el sufrimiento relega a segundo lugar el lograr el placer, es decir, el principio del placer se transforma por influencia del mundo exterior en el principio de realidad. ${ }^{50}$ Freud en este punto crucial de su filosofía se muestra otra vez un teformador (no un revolucionario), aunque no deja de ver los peligros de la creciente limitación de las tendencias instintivas. ${ }^{51}$ (Este tema luego será retomado, Ilevándolo hasta límites impensables para la puudencia intelectual de Freud, por la llamada izquierda freudiana.)

Tanto en el plano de la psicología individual como en el proceso cultural, que Freud considera ucomo una abstracción de orden superior a la de la evolución del individuon, la flitosofía de la vida de Freud es noto. riamente dualista. Así lo reconoce expresamente en Más allá del principio

49. E. Fromm, Sigmund Freud's Mission, op. cit, p. 99.

50. S. Freud, El malestar de la cultura, op. cit., p. 28.

51. S. Freud, «EI porqué de ta guerra», Obras Completas (Madrid), op. cit., p. 3215 . 
del placer. «Nuestra concepción era dualista desde un principio y lo es ahora aún más desde que denominamos la antítesis, no ya instintos del yo e instinto sexuales, sino instintos de vida e instintos de muerte. ${ }^{52}$

Pero esta lucha cósmica entre amor y muerte, entre Eros y Tanatos, se da también en el ser humano mismo (perverso y sublimador), que no es una criatura tierna y necesitada de amor solamente, sino un ser cuyas disposiciones instintivas llevan también su buena porción de tendencias agresivas. La posición de Freud, según Roazen, es pesimista; su fe cientificista le había llevado tempranamente a impugnar por anticientííca la creencia en la libertad y la espontaneidad psicológicas y a reivindicar el determinismo psíquico. Pero ese determinismo, ¿cómo se inserta en una concepción dual, agónica, de la vida humana? No muy fácilmente. Escribe Freud en El malestar en la cultura: «A mi juicio el destino de la especie humana setá decidido por la circunstancia de si, y a qué punto, el desarrollo cultural logrará hacer frente a las perturbaciones de la vida colectiva emanadas del instinto de agresión y autodestrucción. $\rangle^{53}$

Estamos, pues, ante una visión trágica de la vida, inclinada hacia el pesimismo, similar al de los momentos más amargos del Ortega exiliado en Buenos Aires, quien desde el mismo trasfondo nostálgico liberal critica la concepción de los que creen que la sociedad se regula miríficamente, cuando en realidad lo hace lamentable «gracias a que la mayor porción de las fuerzas positivamente sociales tienen que dedicatse a la triste faena de imponer un orden al resto antisocial de la llamada sociedad»..$^{54}$

Es realmente extraordinaria la coincidencia de talante entre la visión freudiana del mundo y la de su gran contemporáneo alemán Max Weber. El héroe capaz de vivir sin ilusiones de Freud se da la mano con el pesimismo heroico de Weber; el principio de la realidad de aquél con la moral de la responsabilidad de éste. Ambos adoptan la misma actítud desilusionada ante la inexorabilidad de nuestra civilización en su camino hacia un fututa de «jaula de hierro». Ambos, en resumen, participan de la misma visión trágica y de la misma concepción dualista del mundo, típica del fin du siècle.

¿De dónde nace esta concepción del mundo? Para algunos estudiosos de la biografia de Weber, proviene de la lucha entre el autoritarismo paterno y la religiosidad materna $o$, si se quiere, de la lucha generacional

52. S. Freud, «Más allá del principio del placer» en Psicología de las masas, op. cit., p. 129.

53. S. Freud, El malestar de la culturat, op. cit., p. 113.

54. José Ortega y Gasset, Las Atlántidas y Del Imperio Romano (Madrid: Revista de Occidente, 1960), p. 112. 
entre padres e hijos burgueses. ${ }^{55}$ Para Luckacs, no es más que «una forma más refunada de combatir al materialismo histótico» por parte de la burguesía."

En nuestra opinión Luckacs tiene tazón en llamar la atención sobre el anclaje burgués en la base de la cosmovisión weberiana; sin duda eso es lo que le hace coincidir con Freud. Pero su explicación es demasiado simple, demasiado unilinear. Otro matxista (muy próximo a él, por cierto) el francés Goldmann, utiliza mejor la clave de lo común de Freud y Weber a través de su estudio de la intelectualidad jansenista, como veremos.

Tanto Freud como Weber son hijos de la burguesía, aunque, por cierto no del mismo estrato ni con situaciones familiares similares. De ambos puede decirse, como dice Coser de Weber, que cesaron de creer en las ideologías que tradicionalmente había justificado la era burguesa pero que fueron incapaces de ofrecer una contraimagen. ${ }^{57} \mathrm{O}$ dicho en términos marxistas que su conciencia se separó de su existencia. Ni Freud ni Weber pertenecian a la pequeña fracción de ideólogos burgueses que, como Marx y Engels, renegaron de su clase. De abi su debilidad, de abi su negación del porvenir, su decir sí y no al mismo tiempo que constituye el nódulo de la concepción dualista y de la visión trágica.

Ese dualismo insalvable no es ni la consecuencia única de una situación familiar conflictiva ni un maquiavelismo de ideólogo burgués. El mérito principal de la obra de Goldmann Le dieu cacbé, ${ }^{58}$ que es un estudio de la intelectualidad jansenista del siglo xvuI, es haber hecho comprender que la visión trágica anida en toda ideología de minotias intelectualmente avanzadas, pero socialmente débiles, que siguen ancladas, por su base económica, en la sociedad de la que son críticos intelectuales. Los jansenistas eran aristócratas o funcionarios de la corona francesa, Weber un vástago de la burguesía alemana imperial, Freud un médico con clientela burguesa y con el status de referencia de la clase profesoral a la que Weber orgulosamente pertenecía.

La jaula de hierro que prevén para el fututo no es más que la proyección de la propia jaula de hierro de su presente, de su propio contorno social, en la que ellos se sienten atrapados.

55. Véase el prólogo de Gerth y Mills a Max Weber, Ensayos de sociología contemporánea (Barcelona: Martínez Roca, 1972) y Arthur Mitzman, The Iron Cage (Nueva York: Grosset y Dunlop, 1969), «Introduction».

56. G. Lukács, El asalto a la razón (Barcelona México: Grijalbo, 1967), pp. 485 a 590.

57. L. Coser, prólogo a la obra de Mitzman, op. cit.

58. Utilizo la edición castellana titulada El bombre y lo absoluto (Batcelona: Península, 1968). 


\section{Más allá de Freud}

Es fácil hacer deporte como lo hace Charles Anderson y otros sociólogos de la nueva sociología americana, destacando el esencial conservadurismo de Freud con referencia a otros aspectos de su obra. ${ }^{59}$ Se procede entonces de forma inversa a la aconsejada por Riessman; es decir, se toma el ropaje de su tiempo y su cultura y se desprecia lo esencial de sus hallazgos cientificos. Este descarte de Freud por parte de algunos marxistas superficiales parece, por otra parte, un mecanismo de defensa dado que el escaso tratamiento de lo psicológico individual es uno de los más notorios vacíos de su teoría. Como bien agudamente acota Freud en su por otra parte burda crítica del marxismo: «es verdad que al abolit la propiedad privada se sustrae a la agresividad humana uno de sus recutsos, sin duda uno muy fuerte, pero de ningún modo el más fuerte de todos». ${ }^{60}$

Ciertamente que se encuentran en la profusa obra de Freud todos los elementos que constituyen el modelo del conservadurismo de derecha. En primer lugar su extremado elitismo, su menosprecio por la miseria psicologica de las masas. «El hecho de que los hombres se dividan en dirigentes y dirigidos - cree Freud- es ura expresión de su desigualdad innata e irremediable. $»^{61}$ «Se trata de una ineludible ley natural» - «el hecho básico de toda sociedad» como escribiría Ortega y Gasset en representación de una idea común a la burguesía intelectual de la época. ${ }^{62}$ Naturalmente entonces la igualdad resulta una «ilusion» de la ideología bolchevique tanto como la religión.

Su concepción del progreso es la tecnológica e individualista del dynamic conservatism, como aparece en este claro texto de Las nuevas lecciones: «una modificación capital del orden social carece de probabilidades de éxito, en tanto que nuevos descubrimientos to hayan intensificado nuestro dominio de las fuetzas naturales y facilitado con ello la satisfacción de nuestras necesidades». ${ }^{63}$ Este elitismo conservador se ve reforzado por la aceptación de la necesidad inescapable de la coacción para el mantenimiento de las instituciones culturales de la civilización, primero en forma externa luego interna. ${ }^{54}$ Incluso la religión mosaica tiene para Freud as-

59. Charles H. Anderson, Toward a New Sociology (Homewood: Dorsey, 1974), pp. $8-10$.

60. S. Freud, El malestar en la cultura, op. cit., p. 72.

61. S. Freud, El porqué de la guerra, op. cit., p. 3213.

62. José Ortega y Gasset, «España Invertebrada» en Obras Completas (Madrid: Revista de Occidente, 1957), vol. III, pp. 103 y 93.

63. S. Freud, «Nuevas decciones...», op. cit., p. 3205.

64. S. Freud, El porvenir de uno ilusión, op. cit., pp. 2963 y 2965. 
pectos eufuncionales como un «progreso de la espiritualidad» que «supone la valoración del trabajo intelectual y renuncias institucionales». ${ }^{65}$

Es en relación al papel de la mujer, como se ha puesto en evidencia hasta la saciedad, donde se observa a un Fteud más apegado a las creencias de la burguesía liberal de principios de siglo. Sus ideas sobre «el afán de masculinidad» o "la envidia fálica» de la niña tanto como sobre la incapacidad de la mujer para la sublimación cultural apenas encubren la ideología de male superiority de la burguesía de su tiempo. ${ }^{\star}$ Por si algo pudiera sobrevivir de ellas, en la actualidad las intelectuales del Women's Liberation Movement se han encargado de recriminarlas como sobrestima* ción de lo sexual y paternalismo.

Creo que el camino de la crítica al ropaje temporal de Freud, además de ser fácil, es infecundo. Otros ideólogos de la derecha cumplen ese papel más inteligente $\mathrm{e}$ inequívocamente.

Pero, ha habido un grupo de seguidores de Freud, los más hetero. doxos, que han sabido tomar sus cabos sueltos y llegar a posiciones radicalmente opuestas. Me refiero a la llamada «izquierda freudiana».

\section{La izquierda freudiana}

Este grupo de intelectuales rescata a Freud -como ha señalado Robinson- de entre los autiutopistas en que había sido colocado por la exégesis conservadora, y explora las potencialidades revolucionarias del psicoanálisis. ${ }^{67}$

Es evidente que en el propio Freud hay suficientes cabos sueltos como para hacerlo inadaptable al orden político y sexual establecido. Freud en algunas ocasiones define el tratamiento psicoanalítico como «liberación del amor reprimido", en otras critica la conducta erótica del hombre civilizado caracterizado por el sello de la impotencia psíquica y llega a identificar a la ciencia misma con «la liberación del placer». ${ }^{68}$ (Según testimonia Jones, Freud soñaba con encontrar un anticonceptivo que «liberara el goce sexual de toda complicación». . $^{69}$ El propio Freud le escribe a un amigo: «Yo propugné una vida sexual incomparablemente más libre, si

65. S. Freud, «Moisés y la religión monoteista», op. cit., p. 178.

66. Véase S. Freud, «Sobre la sexualidad femenina» en Tres ensayos sobre la teoris sexual, op. cit., p. 139, y El malestar en la cultura, op. cit., p. 60 .

67. Paul T. Robinson, The Freudian Left (Nueva York: Harper, 1969), p. 3.

68. S. Freud, Psicoanálisis del arte (Madrid: Alianza, 1973) y Ensayos sobre la xida sexual y la teoría de la neurosis, op. cit., pp. 85 y 69.

69. E. Jones, Vida y obra de S. Freud, op. cit., vol. I, p. 297. 
bien por mi parte he hecho muy poco uso de tal libertad. $\rangle^{70}$ Es notable que en un cierto momento de su discurso Freud, como Engels, considere a la familia y al matrimonio monogámico como un obstáculo al progreso sin atreverse luego a sacar las consecuencias de tal aseveración. ${ }^{71}$

El «freudismo» como una doctrina radical diferente del psicoanálisis no se limita a los seguidores izquierdistas de Freud, como Reich, Roheim y Marcuse, sino que es parte sustancial de la llamada «teoría crítica de la sociedad» de la Escuela de Frankfurt.

Según están conformes en reconocer varios estudiosos de la famosa escuela alemana, como Therborn, Rusconi, Jay, Osborn y, entre nosotros, Castilla del Pino, una de sus características es considerar a Marx y a Freud complementarios $\mathrm{e}$ interpretar a ambos como una lógica que está en las antípodas del pesimismo antiutópico, o sea, que está con el optimismo utópico revolucionario que en esencia, como dice Goldmann, significa siempre «una apuesta al futuro». En este sentido la interpretación de los de Frankfurt significa invertir el psicologismo ortodoxo freudiano tanto como Marx lo bizo con la dialéctica begeliana. En la conocida expresión de Marcuse: las categorías psicológicas devienen categorías políticas. $\mathrm{O}$, como dice Horkheimer: Freud «buscó el todo en la parte más pequeña, lo más amplio en lo individual». ${ }^{72}$

Esta posición supone una crítica del revisionismo frommiano en cuanto a sociologización del psicoanálisis. «Cuanto más se oponen a la psicologización de la teoría de la sociedad, tanto menos significan, por otra parte, una socialización de la psicología», escriben Adorno y Horkheimer en el prólogo de los trabajos que el Instituto de Investigación Social de Frankfurt dedicó a Freud en el centenario de su nacimiento. ${ }^{73}$

De todo el grupo de intelectuales europeos esforzados en conciliar Freud con Marx es a mi juicio Marcuse el más importante. No sólo porque es el único que pertenece a la vez a la izquierda freudiana y a la escuela de Frankfurt, sino por el alcance y la influencia de su pensamiento. Él, como nadie, ha sabido reunir en su obra el radicalismo sexual y el radicalismo político tanto en sustancia como en estilo. Adorno y Horkheimer nunca llegaron $\tan$ lejos. Se limitaron a convertir a Freud, como dice Martin Jay, en «un profeta de las tinieblas».

70. Ibidem, vol. 2, p. 256.

71. Véase S. Freud, El malestar en la cultura, op. cit., p. 60, y F. Engels, El origen de la familia, la propiedad privada y el Estado, op. cit.

72. T. W. Adorno y W. Dirks, Freud en la actualidad (Barcelona: Barral, 1971), p. 58 .

73. Ibidem, p. 9. 
En Eros y civilización ${ }^{74}$ Marcuse abandona la crítica negativa de la sociedad industrial avanzada, característica de sus obras primeras, y presenta un proyecto alternativo. Su instrumento es la filosofía freudiana y la lectura hegeliana de Freud. Porque a Mercuse lo que le interesa no es el psicoanálisis (que considera atrapado por la contradicción entre el deseo de mayor felicidad individual y el desarrollo de una sociedad represiva antiliberal), sino «la filosofía del psicoanálisis». Lo que le importa a Marcuse no es la curación individual sino el desorden general de quien aquella en definitiva depende.

Nuestra civilización es represiva y resultado de una lucha contra la libertad. Ese es el «gran suceso traumático» en el desarrollo del hombre. Pero si en la sociedad primitiva, la sociedad de la escasez, era necesaria la represión de los instintos biológicos para construir la civilización, una vez desarrollada genera una «represión excedente» al nivel sociológico, que garantiza la continuidad de la dominación del orden establecido. A diferencia de Freud, Marcuse cree en la posibilidad futura de establecer una sociedad no represiva, una sociedad que después de creada la cultura pueda hacer una "regresión» a lo instintivo y liberarse del progreso. Esta situación utópica liberada de la angustia del dolor y la memoria reprimida, que Freud sólo entrevió en el arte, Marcuse cree que es generalizable a toda sociedad avanzada.

Desde un trasfondo althusseriano el sociólogo argentino Eliseo Verón ha hecho una aguda crítica de la alternativa «positiva» que ofrece la ideología marcusiana. Para Verón, Marcuse retrotrae la teoría a la «antesala del marxismo" pues la crítica a la sociedad industrial lo lleva, ya que no a una justificación del Estado como en el caso de Hegel, a un nuevo principio metafísico: el Eros. Como este principio es rescatado de la naturaleza y no de la sociedad ello convierte a la ideología de Marcuse en una especie de «socialismo biológico». En realidad para Verón es una contraideología, un mecanismo de defensa similar al de neurosis individual. Es, escribe Verón, «una recorrida a contrapelo de la historia que sólo puede hacerse neuróticamente, vale decir, al precio de un resurgimiento de lo irracional social disfrazado de naturaleza». ${ }^{75}$

La crítica de Verón termina irónicamente señalando que «la combinación de un pesimismo generalizado y radical acerca de la sociedad con una esperanza fundada en la esencia biológica del hombre es uno de los rasgos sustanciales del pensamiento de la derecha».

74. Utilizo la edición de Seix y Barral (Barcelona, 1969).

75. La primera versión de esta crítica de E. Veron apareció en «Ideología de Marcuse» en la revista porteña Los Libros, núm. 3 (septiembre 1969). 


\section{¿Freud superado?}

La crítica de la izquiezda llegó después. En realidad Freud tuvo que luchar toda su vida con las acusaciones de «inmoralidad» de que fuera objeto por parte del pensamiento tradicional y del establisbment médico. Tal crítica llega por cierto hasta casi nuestros días. En una revista psiquiátrica profesional española en 1956 aún se puede leer que Fread dio origen a una moral arbitraria «recusable no sólo desde un punto de vista religioso sino axiológico» que negó la conciencia moral y que ha resultado jen un aumento de la delincuencia infantil y la crisis de la educacion! ${ }^{76}$ Después, cuando este tipo de crítica perdió eficacia ante la evidente aceptación general de los puntos de vista freudianos, entonces la crítica conservadora pasó, sin solución de continuidad, a sostener que la obra freudiana, que nunca conocieron, había sido superada.

Es evidente la vinculación entre las ideas de Freud y el contorno social y cultural que le tocó vivir. No sólo to han remarcado así muchos estudiosos de su obra sino que surge palmariamente de sus propios textos. En la interpretación de sus propios sueños podemos observar la penetración en su inconsciente de los mecanismos de la represión de la sociedad vienesa, $\tan$ curiosamente similates a los de nuestra propia sociedad, ${ }^{7}$ y la relación entre ellos y sus construcciones teóricas como los conceptos de represión, censura y disimulación ideológica.

Hablar en España, bace veinte años, como lo bizo algún notable escritor, sobre la agonía o la terminación del psicoanálisis no parece serio. Peor aún: es continuar la tradición del pensamiento contrarreformista por la que según el juicio lapidario de Aranguren perdimos jirones enteros de realidad en defensa de cuestiones de principio.

Ciertamente que bay un más allá de Freud y de su psicoanálisis. El mismo Freud que reconoce manifiestamente la provisionalidad de todo saber, lo aceptaría aunque no gustoso. Ciertamente que su filosofia es discutible y su sociología, según bemos demostrado, más endeble todavía. Pero los ballazgos más sustantivos del psicoanálisis sólo son revisables desde una base social que baya cruzado el umbral que él primero cruzó y que baya reobrado sobre la nueva realidad que Freud saco a lo superficie. Solamente desde una sociedad que baya asimilado la nueva concepcibn sobre la niñex, el sexo, la anormalidad, la bomosexualidad, o las relaciones

76. Véase $R$. Vidal Folch, «La repercusión del psicoanálisis en la sociología modernas en Revista de Psiquiatría y Psicología Médica de Europa y América Latina, tomo II, núm. 8 (1956).

77. Véase La interpretación de los sueños, op. cit., pp. 203, 204, 209-210, entre otras, yol. I. 
sexuales paterno-filiales prede plantearse la depuración de lo que en el primer paso treudiano babia del barro de su sociedad vienesa.

Antes es epistemológicamente imposible. En las sociedades hispanoparlantes está ahora llegando Freud, si no a la totalidad de la población, a sus círculos letrados más amplios. Sólo ahora se pueden ver en los kioscos de las calles de Madrid o Río de Janeiro las ediciones populares de las ya vetustas obras de Freud hasta hace poco tiempo privilegio de ediciones costosas y limitadas. Sólo ahora, por tanto, estaremos en condiciones de medir cual ha sido el impacto de la revolución freudiana en algunos, no todos, los sectores sociales y podremos entonces hablar de su superación o no con los pies en la tierra de nuestra propia realidad. Hacerlo antes, antes de que nuestro mundo social haya cruzado los umbrales que Freud mentalmente cruzo, es colocar la carreta superestructural antes del buey del cambio social. Y eso es no sólo un desatino sociologico sino un acto más del confusionismo calculado que todos -como dogal ideologicobemos padecido en nuestra bistoria individual y en nuestra bistoria colectiva.

Juan F. Marsal

Departamento de Sociología

Universidad Autónoma de Barcelona

Bellaterra, Barcelona 